\title{
International coopetition for innovation: Are the benefits worth the challenges?
}

\author{
Vladimir Vanyushyn ${ }^{1} \cdot$ Maria Bengtsson $^{1} \cdot$ Malin H. Näsholm $^{1} \cdot$ Håkan Boter $^{1}$
}

Received: 10 February 2017 / Accepted: 27 November 2017 / Published online: 12 December 2017 (C) The Author(s) 2017. This article is an open access publication

\begin{abstract}
International coopetition has rarely been studied in relation to innovation. Further exploration of effects of international coopetition, i.e. the pursuit of simultaneous cooperation and competition, on a firm's innovation performance is especially important as such a relationship is challenging with a high propensity to fail. This observation formed the point of departure for this study, which aims to increase the understanding of the effects of international coopetition on firm innovativeness and how these effects are conditioned on the magnitude of the organizational adjustments a firm introduces. We use an unbalanced panel of 9839 firms that participated in four waves of the Swedish Community Innovation Survey between 2008 and 2014 as our empirical base. We illustrate that firms that cooperate with competitors internationally are more likely to exhibit higher propensity to introduce radical innovations, yet this effect is conditioned upon the magnitude of organizational adjustments. Overall, our study contributes to the understanding of the implications of international coopetition and what a firm needs to benefit from it.
\end{abstract}

\footnotetext{
A previous version of this paper was awarded the best paper award within "The Relationship between Coopetition and Innovation/Entrepreneurship" track at the 7th Global Innovation and Knowledge Academy (GIKA) Conference, Lisbon, Portugal, June 28-30, 2017. The authors acknowledge Manish K. Srivastava for his work and insights in database development.
}

Vladimir Vanyushyn

vladimir.vanyushyn@umu.se

Maria Bengtsson

maria.bengtsson@umu.se

Malin H. Näsholm

malin.nasholm@umu.se

Håkan Boter

hakan.boter@umu.se

1 Umeå School of Business and Economics, Umeå University, 90187 Umeå, Sweden 
Keywords Innovation - Coopetition - International coopetition $\cdot$ Radical

innovation · Incremental innovation · Organizational innovation

JEL Classification $\mathrm{L} 14 \cdot \mathrm{C} 83 \cdot \mathrm{M} 10$

\section{Introduction}

Zhang et al. (2010) argued that both cooperation and competition, i.e. coopetition (Brandenburger and Nalebuff 1996; Bengtsson and Kock 2000), exist in many international alliances and demonstrated that these alliances contribute more than domestic ones to firm innovation (Zhang et al. 2010), as they provide more complementary resources in the form of "different technologies, know-how, connections, locations, capacities, and distribution channels" (McCutchen et al. 2008, p. 194). When international alliances are formed with competitors, the similarity between the firms can be assumed to increase their in-learning (the transferring and building of explicit knowledge) from the alliance (c.f. Kraus et al. 2017; Bouncken and Kraus 2013; Bouncken et al. 2016). This form of knowledge acquisition in coopetition has been found to be beneficial for focal firms' innovativeness (Ritala and Hurmelinna-Laukkanen 2013). International coopetitive relationships can, therefore, be more beneficial yet more challenging to manage than domestic ones. Although coopetition has been recognized as an inherent part of the international business landscape (Luo 2004), international coopetition has rarely been studied in relation to innovation, with two notable exceptions: Zhang et al. (2010) as well as Schmiele and Sofka (2007). We draw on literature on both alliances and coopetition to explore the relationship between these relationships and innovation. The key question raised in this paper is whether a broader international scope of coopetition is beneficial for innovation or the additional complexities of international coopetition hamper firms' innovativeness.

We argue that international coopetition relationships are challenging to manage and uphold for two main reasons. First, international alliances are facing international risks, which include firm-specific and environmental uncertainties such as political, economic, and social uncertainties in a particular country/location (Miller 1992) that, if not managed, can lead to a dissatisfactory performance or an alliance failure. Cultural differences and dissimilar political, institutional, legal, and language backgrounds make communication between partners difficult and increase the chance of misunderstandings (McCutchen et al. 2008). Second, coopetition is per se paradoxical and tension filled as the firms interact in accordance with two contradicting logics (Chen 2008; Fernandez et al. 2014). Coopetitive tensions on an interorganizational level have been described being, for example, between value creation and appropriation, between knowledge sharing and preventing knowledge leakage, and due to differences in the strategies and goals of each partner (Fernandez et al. 2014). The cognitive difficulty and emotional ambivalence experienced when working with these contradictions create tension that is difficult to cope with on the individual level (Raza-Ullah et al. 2014; Raza-Ullah 2017a, b). The experienced tension 
in coopetition can, therefore, cause aggravation in the relationship between firms (Fang et al. 2011), and many coopetitive relationships fail or dissolve prematurely as a result (c.f. Das and Teng 2000). The contradictory nature of coopetitive relationships can explain why research has been ambiguous about the effect of coopetition on innovative outcomes and, particularly, whether it is more beneficial for radical or incremental innovations (Bouncken et al. 2017; Ritala and Sainio 2014).

Fernandez et al. (2014) argued that the challenges of coopetition require that firms manage tensions and adjust the relationship accordingly. However, changes that are required in the organizations' routines and practices to manage coopetition for innovation and, in particular, international coopetition, have not been studied. Given how demanding such relationships can become, managing them while introducing organizational innovations is likely to be a challenging task for firms' managers and might reduce firms' ability to benefit even from superior knowledge and resources provided by international coopetitive partners. Thus, further exploration not only of the relationship between international coopetition and innovation but also of the effects of organizational innovation on this relationship is required.

Hence, this paper aims to increase the understanding of the effects of international coopetition on firm innovativeness and how these effects are conditioned on organizational innovations a firm introduces. We use an unbalanced panel of 9839 firms based on a micro-matched data set that combines four waves of the Swedish Community Innovation Survey conducted between 2008 and 2014, firm register data and firm-specific employee data to test our hypotheses using bi-probit and panel logit specifications. Our findings extend existing research on coopetition and innovation in three ways. First, we demonstrate that firms involved in domestic coopetition have a higher rate of incremental innovations and that only a broader scope of international coopetition is associated with more radical innovations. Incremental innovations are operationalized as new-to-firm innovations, whereas new-to-market innovations are taken to be more radical innovations as they require a more fundamental departure from the existing technologies and capabilities in a firm (Dewar and Dutton 1986; OECD 2005; Ritala and Hurmelinna-Laukkanen 2013). Second, we elucidate the effect of organizational innovations, i.e. actual changes in organizational routines and practices, on firms' ability to manage international coopetitive relationships. Finally, we indicate how international coopetition intensifies the challenges inherent in such relationships and enables higher rates of radical innovations.

\section{Theory and hypotheses}

\subsection{Cooperating with competitors for innovation}

Coopetition, which is the simultaneous pursuit of cooperation and competition between firms (Bengtsson and Kock 2000; Gnyawali and Park 2011), has become an increasingly common business practice (Baumard 2009; Bouncken et al. 2015) that arguably impacts innovation (c.f. Mention 2011; Ritala 2012). Zhang et al. (2010) argued that cooperation and competition coexist in most inter-firm relationships and represent distinct drivers that affect the outcome of the relationships. The two 
drivers are different but equally important, and their combination makes coopetition beneficial for a firm's innovative performance. The idea is that dual benefits can be achieved: access to resources through cooperation and the pressure to improve provided by competition (Bengtsson and Kock 2000; Park et al. 2014). On the one hand, partners jointly create new knowledge or acquire knowledge, from one another, that is needed to further develop technology and markets. On the other hand, partners pressure each other to use this knowledge to create and further develop their own products and processes in a better manner than that of their partner (Wu 2012, 2014). Competition and cooperation thereby become two distinct drivers of innovation (Zhang et al. 2010), which are combined in coopetitive relationships.

While it is often argued that coopetitive strategies positively contribute to innovation (cf. Ritala and Hurmelinna-Laukkanen 2009), research has been somewhat ambiguous about the effect of coopetition on innovative outcomes (Bouncken et al. 2017; Ritala 2012). Quintana-Garcia and Benavides-Velasco (2004) demonstrated that coopetition, along with other relationships, has a positive impact on innovation, whereas other studies found no significant increase in innovation performance, or even negative effects of coopetition on innovation (Mention 2011). Coopetition can, however, also involve higher risks than non-competitive collaborations (Cassiman et al. 2009; Nieto and Santamaría 2007). Other negative consequences such as fear of opportunism and knowledge leakage (Park et al. 2014) can also explain why coopetition not always has a positive impact on innovation (Ritala and HurmelinnaLaukkanen 2009). Park et al. (2014) and Wu (2014) argued that coopetition has an inverted-U relationship with innovation, as beyond a certain point, the coopetitive tensions become too high, thereby limiting knowledge sharing and hampering innovative outcomes.

An important aspect to consider when examining the relationship between coopetition and innovation is the degree of novelty of innovation. This can be done through distinguishing between incremental innovation, which requires minor changes and development in existing products or technologies, and more radical innovations, which require more fundamental changes and can be the basis for completely new products (Dewar and Dutton 1986; Ritala and Hurmelinna-Laukkanen 2013). Although there are strong conceptual arguments for coopetition being beneficial for both incremental and more radical innovations (Ritala and HurmelinnaLaukkanen 2009), some empirical studies indicated that coopetition has a negative effect on innovation novelty (Bouncken and Kraus 2013; Mention 2011; Nieto and Santamaría 2007). Researchers also demonstrated that different managerial antecedents of coopetition, such as alliance strategy and function, affect coopetition and subsequently firms' radical as well as incremental innovation (Bouncken and Fredrich 2012). Furthermore, the choice of how many firms to coopete with and the distance to these firms seem to have different effects depending on the objectives of innovation-related coopetition. Yami and Nemeh (2014) suggested that dyadic coopetition is more suitable for incremental improvements and that coopetition with multiple partners is appropriate when the motives are to obtain radical technological development. Ritala and Hurmelinna-Laukkanen (2013) suggested that for radical and incremental innovations, a different emphasis is needed, in terms of knowledge sharing and knowledge protection, for firms to benefit from coopetition. Bouncken 
et al. (2017), in a study of new product development, found that the benefits of coopetition are primarily in the launch phase of radical innovation, whereas incremental innovation benefits from coopetition in both pre-launch and launch phases.

In summary, the enhancement of firms' innovative performance has been identified as one of the key reasons for why firms choose to get involved in coopetition (c.f. Mention 2011; Ritala 2012), but the studies exhibit mixed results and highlight that other factors affect the relationship between coopetition and innovation. Empirical studies on innovation-related coopetition have considered the context by focusing on relationships in different industries and in different countries. For example, coopetition is argued to affect innovation positively in high-technology sectors (Ritala and Hurmelinna-Laukkanen 2009) and under conditions of technological uncertainty (Bouncken and Kraus 2013). However, these studies do not explicitly explore how international coopetition affect firms' radical and incremental innovation.

\subsection{International coopetition for innovation}

Although many empirical studies of coopetition for innovation are conducted in an international context (Gnyawali and Park 2011; Park et al. 2014; Quintana-Garcia and Benavides-Velasco 2004; Yami and Nemeh 2014), few studies explore the link between international coopetition and innovation. The assumed importance of international coopetition can both be explained by the advantages obtained by coopetition (discussed above) and by advantages of international alliances. We propose two explanations for the positive link between international coopetition alliances and innovative performance. First, partners from different countries provide complementary strategic resources that can contribute to a firm's innovation capability (Lew and Sinkovics 2013; McCutchen et al. 2008). Allying with international partners could be beneficial for innovation, as the partners can provide access to more diverse resources and knowledge (Sampson 2007). Sok and O'Cass (2011) found that resource and capability complementarities among partnering firms are positively related to the firms' innovative performance and, as the differences are larger among international than among domestic firms, international alliances can be assumed to be more important for innovation.

Second, when firms ally with international partners to access external knowledge, there is less availability and higher costs involved in the process of collecting, pooling, and using the knowledge and resources due to geographical and cultural distances. Thus, Zhang et al. (2010, p. 77) argued that "knowledge acquired from international alliances is likely to be valued more than knowledge from domestic alliances and thus lead to enhanced knowledge creation and innovative performance" as firms are more committed and ready to invest in the relationship to benefit from it. Furthermore, Schmiele and Sofka (2007) proposed that the experience of cooperating with firms internationally, for example, with customers or suppliers, develops capabilities important for managing coopetition internationally. Geographic diversity may generate experiences and give positive learning effects, which enhance the capacity to absorb, analyze, and develop effective capabilities 
to assimilate the diverse flow of knowledge streams into new products and services (Autio et al. 2000). Similarly, a firm's experience of coopetition is argued to be part of the firm's coopetition capability (Gnyawali and Park 2011) that may be transferable internationally. Accordingly, firms that are involved in many coopetition relationships with international firms develop experiences that might enhance their international coopetition capability, making it easier for them to benefit from such alliances and improve innovation.

However, the cultural differences when cooperating with a competing firm abroad increase the risks and uncertainties involved as there may be differences in perceptions of trust, innovation practices and other organizational processes (Schmiele and Sofka 2007; Hultén and Vanyushyn 2010). In international coopetition, firms need to manage the international risk linked to uncertainties due to challenging political, economic and legal differences (c.f. Kogut and Singh 1988; Nielsen 2007). Nielsen and Nielsen (2009) argued that the likelihood of failure is high due to dissimilarities between partners. The international nature of the relationship increases the complexity and uncertainty involved, and one example is that the enforcement of intellectual property rights differs between countries, thus increasing the risk related to international technology alliances (Kranenburg et al. 2014). In addition, monitoring the relationship with partners in countries with a large institutional distance is difficult and costly, and the distance also makes conflict resolution more difficult (Davidson and McFetridge 1985). The cultural distance has been found to be negatively related to performance as it increases the risk of mistrust, misunderstandings, miscommunication and conflicts (Glaister and Buckley 1999; Kim and Parkhe 2009; Makino et al. 2007). Furthermore, geographic distance decreases the quality of information flows and communication (Ghemawat 2001) and exacerbates information asymmetry between partners.

\subsection{Development of hypotheses}

Based on the presented review, we suggest that engaging with a broader scope of international coopetitive partners affects firm innovativeness and that such effect is conditioned upon the magnitude of organizational innovations. With this observation in mind, Fig. 1 presents the overall research model that guides our hypotheses development for further empirical testing.

Zhang et al. (2010) are one of few exceptions who directly studied differences between domestic and international coopetition alliances' impact on innovation. They illustrated that knowledge acquisition through international coopetition was directly linked to innovation. Although cultural differences are argued to lead to alliance failure (Yan and Zeng 1999), international alliances exhibit better performance than domestic alliances (McCutchen et al. 2008). The number of foreign markets entered also influences the extent to which the firms can gain knowledge and resources and develop products, services as well as routines (Zahra et al. 2009). A broad international market scope implies that firms are involved in set-ups of foreign activities, including networking with several different partners, and these undertakings are tapped into multiple international markets in parallel (Li et al. 2012; Taylor 


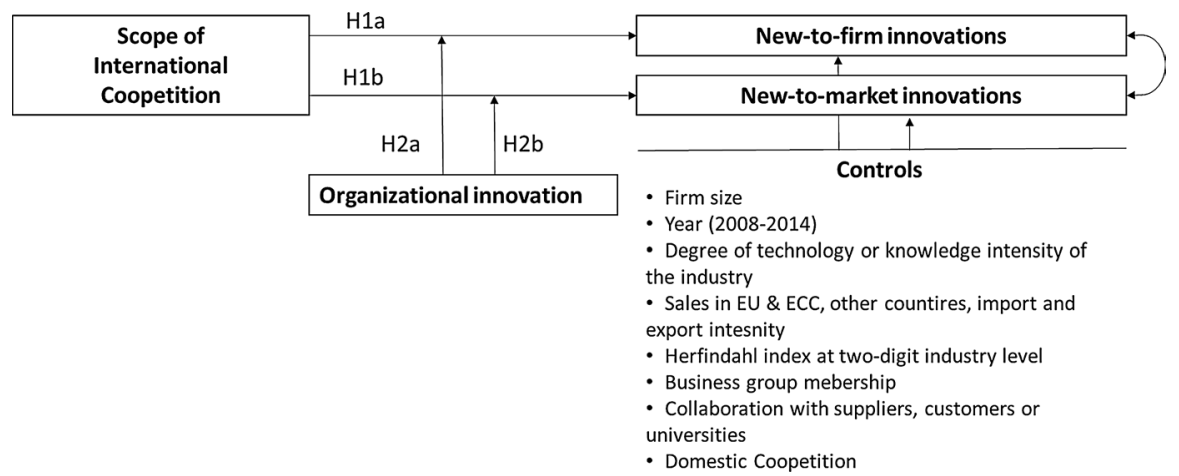

Fig. 1 Research model

and Jack 2013). Beamish and Kachra (2004) argued that firms' international experience can explain why the firms gain innovation advantages from international relationships despite the cultural distance between the partners. The experience obtained through involvement in a broad scope of international relationships enhances a firm's skills in risk management and subsequently improves their innovation capability (c.f. Chetty and Stangl 2010).

Empirical studies addressing the impact of coopetition on radical and incremental innovation have reported contradictory results, which may be due to different dimensions of radicalness being measured (Ritala and Sainio 2014). Mention (2011, p. 51) found that coopetition has a negative influence on innovation novelty as firms are unwilling to share knowledge needed for such innovation and that coopetition "supports an imitation strategy rather than a willingness to introduce new to the market innovation". In line with this, Bouncken et al. (2017) demonstrated that, based on a study of knowledge intensive industries, coopetition is generally more positive for incremental innovation. By contrast, Bouncken and Fredrich (2012) found coopetition to be more beneficial for radical innovation than for incremental innovation in a high-technology industry and that trust and dependency is what increases the benefits for incremental innovations. Bouncken and Kraus (2013) argued that although coopetition can be beneficial for radical innovation, it can be negative for the development of more revolutionary innovations, which could be due to the risks for opportunistic behavior when sharing knowledge as well as knowledge- and power asymmetries for the studied SMEs. In general, resource similarity and similar knowledge domains make competitors more appropriate partners for incremental rather than for radical innovations (Ritala and Hurmelinna-Laukkanen 2009). However, as previously argued, partners from different countries provide complementary strategic resources (Lew and Sinkovics 2013; McCutchen et al. 2008), and a broader scope of international coopetition may, therefore, benefit radical innovation. This leads us to formulating the following hypotheses:

Hypothesis 1a Broader international scope of coopetition is positively associated with new-to-firm innovations. 
Hypothesis 1b Broader international scope of coopetition is positively associated with new-to-market innovations.

It is important to acknowledge that international coopetition is a complex and challenging relationship, even though we have hypothesized that international coopetition is beneficial for innovation. To be able to benefit from international coopetition, it is important for a firm to adjust by developing internal processes, routines, skills, and structures that enable it to manage international risk (Schmiele and Sofka 2007). Furthermore, to manage coopetition, the organization needs to understand and cope with tension, be able to adjust the nature and scope of the relationship, as well as be able to recognize and respond to opportunities and challenges (Fernandez et al. 2014). As previously discussed, coopetition between competitors in different nations may be even more complex to manage (Gnyawali and Park 2011). Firms have to develop effective governance structures to overcome barriers and exploit benefits from participation in international coopetition for innovation. Over time, firms can learn to manage innovation relationships and develop their mechanisms and routines for managing them to obtain better results (Love et al. 2014). Routines and processes need to be developed that increase the absorptive capacity to share knowledge and learn from others and thereby improve innovation behavior (Cohen and Levinthal 1990; Ritala 2012) as well as mechanisms to avoid opportunistic behavior and unintended knowledge leakage (Gast et al. 2015). However, McCutchen et al. (2008) argued that firms are more careful when choosing international partners than when partnering with domestic firms, as they know that these relationships are difficult to manage. They might, therefore, select firms that are similar to them in certain respects to reduce the need for organizational alignment to enable a fruitful cooperation.

Following the above discussion, we propose that firms involved in international coopetition need, to a higher or lower extent, to develop new business practices or models for organizing activities as well as introducing new methods for organizing responsibilities and decision-making, and new methods for organizing external relationships with other firms or public institutions. Kraus et al. (2012) illustrated that such organizational innovations have a positive effect on innovation. They argued that firms need to update structures and processes to be innovative and not to stagnate. Though organizational innovation directly affects innovation positively, given how demanding coopetitive relationships are, managing them while changing an organization, its routines and processes is likely to be a challenging task for the firm's managers and reduce the firm's ability to benefit from knowledge and resources provided by international coopetitive partners. Hence, we formulate the following hypotheses:

Hypothesis 2a The greater the number of organizational innovations a firm introduces, the lower the impact of international coopetition scope on new-to-firm innovations. 
Hypothesis 2b The greater the number of organizational innovations a firm introduces, the lower the impact of international coopetition scope on new-to-market innovations.

Naturally, our research model also includes a range of firm- and industry-specific control variables that the literature has found to affect a firm's propensity to introduce new-to-market and new-to-firm innovations, particularly studies conducted in similar research contexts (Estrada et al. 2016; Le Roy et al. 2016; Ritala and Hurmelinna-Laukkanen 2009): firm size, industry characteristics in terms of technology and knowledge intensity, industry competitiveness captured using Herfindahl index, as well as alternative collaborations with suppliers, customers and universities. Considering the nature of our independent variable-scope of international coopetition-we also control for firms' involvement in domestic coopetition and international business exposure to account for the potential confounding effects.

\section{Research methodology}

The data for the study came from a data set, micro-matched at the firm-ID level that combines four waves of the Swedish Community Innovation Survey (CIS) that covers years 2008-2014, firm register data and firm-specific employee data for the same time period. The CIS data were collected from participating EU and ESS member states every two years in a cooperative exertion between OECD and Eurostat with the purpose of providing information on facets of innovation activities in firms, different innovation types and innovation costs for firms. The CIS relies on a large sample of firms with 10 and more employees and examines the firms' innovation practices, including cooperation with different partners, and follows the principles and conceptualizations outlined in the Oslo manual (OECD 2005), which is a set of guidelines for collecting and interpreting innovation data in EU member states.

The resulting data set is an unbalanced panel that includes 9839 firms and 29,564 firm-year observations. The key dependent variables (DVs) are binary variables capturing a firm's introduction of new-to-market and new-to-firm innovations, both based on CIS queries of whether a firm has introduced either a new good or service to the market before competitors (hence new-to-market) or a new good or service that is essentially the same as a good or service already available on the market (OECD 2005, p. 58). The independent variable (IV) is the firm's scope of international coopetitive relationships, based on the direct CIS query and operationalized as a sum of coopetitive relationships $\sum_{i}^{n} r_{i}$ in $i \subset$ [0;4] geographical areas ("Europe", "USA", "China or India", and "all other countries"); the variable assumes the value of 0 if a firm had no international coopetitive relationships. The moderator variable Organizational Innovation is a sum of organizational changes (based on a CIS query of whether a firm has undergone major changes in organizing activities, responsibilities and decision-making, as well as external relationship handling) a firm introduced, which also assumes a value of 0 if no organizational changes happened.

Control variables include firm size, measured as log of number of employees; degree of technology or knowledge intensity of the industry classified into 
high-technology, medium-high-technology, medium-low-technology, low-technology manufacturing firms and high-technology, knowledge-intensive and less knowledge-intensive services (OECD 2011), presence on the European and world markets; import and export intensity modeled as log of the transaction sum; the Herfindahl index computed as at a two-digit industry level; a dummy variable assuming a value of 1 if a firm is a part of a business group, dummy variable that captures collaboration with suppliers, customers or universities; and a dummy variable domestic coopetition that assumes a value of 1 if a firm cooperated with competitors on the domestic market; and seven dummies (2008-2014) to capture the effect of the datacollection year.

The average firm in our sample has 46 employees and is 16 years old; hence, most firms are small and medium-sized enterprises. Firms are found in all industries, with most firms coming from knowledge-intensive services (24\%) and medium-technology manufacturing (31\%). Table 1 presents means, standard deviations and correlations among the DVs, IV, as well as moderator and control variables used in the model. Note that even though correlations among binary variables are somewhat difficult to interpret, the pattern and magnitude of correlations does not give reasons to suspect multicollinearity to be a concern.

\section{Results}

Given that incremental and radical innovation efforts are likely to be affected by a similar set of unobservable factors and are correlated $(r=0.41)$, we test our hypotheses by specifying a bivariate probit model (Greene 2008) that allows for correlation of cross-equation disturbances. We estimate the model using the robust cluster variance estimator with errors clustered at firm ID level and year dummies included. Table 1 presents the estimation results for Model 1, which does not include the interaction effect, and Model 2, which includes the interaction effect between Organizational Innovation and international coopetitive relationships. All models are highly significant overall, with $p<0.000$. International coopetition has a positive effect on new-to-market innovations, thus supporting $\mathrm{H} 1 \mathrm{~b}$, but not on new-to-firm innovations (H1a). Inclusion of hypothesized interaction effects results in a statistically significant improvement in the model fit; the interaction terms are significant with a negative sign for both new-to-market $(\beta=-0.039, p<0.05)$ and new-to-firm $(\beta=-0.046, p<0.01)$, thus yielding support for hypotheses $\mathrm{H} 2 \mathrm{a}$ and $\mathrm{H} 2 \mathrm{~b}$.

To ensure the robustness of the results, we conducted a number of post hoc analyses and alternative specification checks. First, we tested our hypotheses using random-effect and population-averaged panel logit specification with lagged values of dependent variables $\mathrm{DV}_{\mathrm{t}-1}$ (Greene 2008), to account for the firms' prior experience in innovation introduction. Table 3 presents the estimates. The substantive results are the same as in the bi-probit model, with coefficients retaining their signs and significance levels. However, even though it retains its direction, the interaction between organizational innovation and international coopetitive relationships becomes insignificant by conventional levels in case of the new-to-firm innovations. Excluding the lagged DV, however, produces results fully similar to Model 2. 


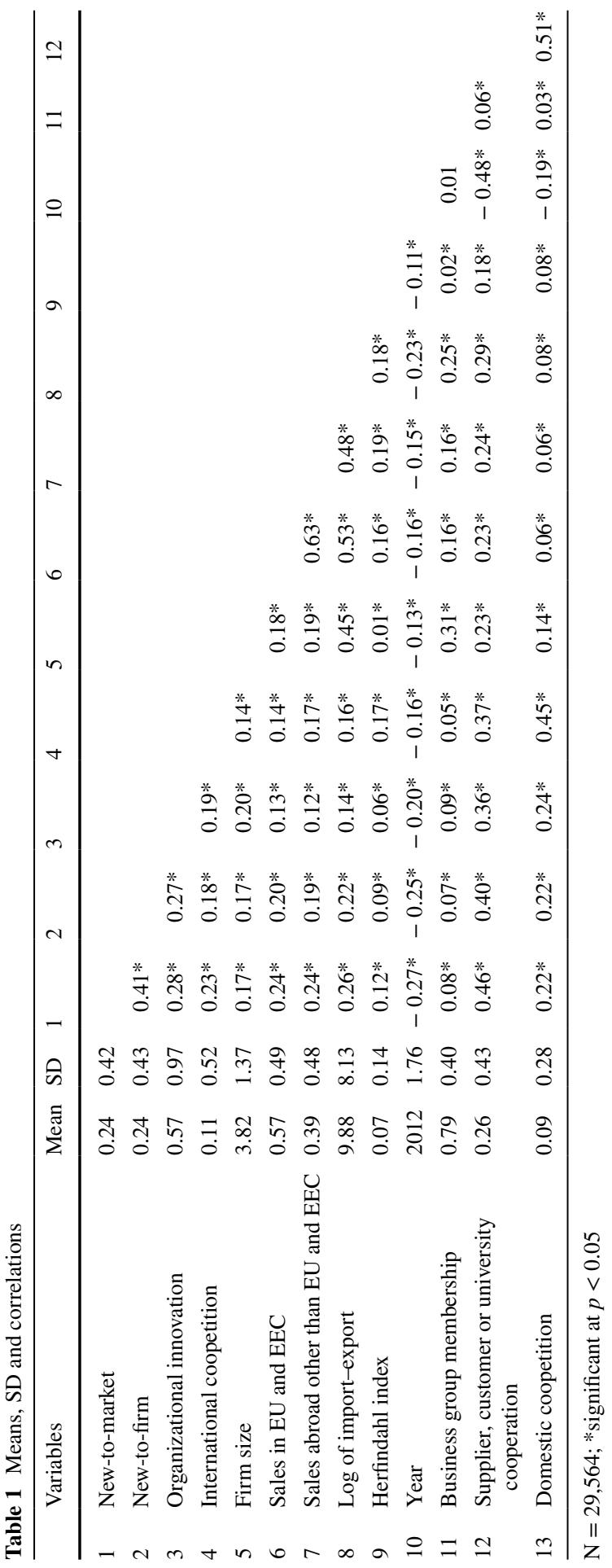


We also estimated the model controlling for the knowledge base of the firm (Estrada et al. 2016), measured by proportion of employees with 3 or more years of full-time university studies. This variable is not available for all firms, and it reduced the sample size. As expected, firm knowledge base had a positive effect on both innovation types; the results of the Models 1-6 remained the same, with coefficients retaining their direction and significance. Finally, the results remained stable when we controlled for the selection that is present in the CIS's structure, where only firms that have undertaken any form of innovation effort respond to a cooperation set of questions by including the inverse Mills ratio (following a procedure suggested by Cader and Leatherman 2011) generated by a firm's equity size, turnover, and localization, as a parameter in the model. Overall, we conclude that the results are stable and are not affected by variables and model specification choice.

\section{Discussion and conclusions}

Driven by the general lack of studies on international coopetition as well as ambiguous results on the relationship between coopetition and innovation outcomes, we investigated the effects of international coopetition in a large-scale representative sample of Swedish firms. The review of literature resulted in the formulation of four hypotheses that posited that firms cooperating with competitors internationally are more likely to exhibit higher propensity to introduce new-to-market and new-to-firm innovations and that such effect is conditioned upon the magnitude of organizational changes that a firm undergoes.

First, we demonstrate that firms involved in international coopetition are more likely to introduce new-to-market innovations, as expected from $\mathrm{H} 1 \mathrm{~b}$, but not newto-firm ones; this is against H1a. These results are in line with findings of Belderbos et al. (2013) that even as firms get involved in international relationships to access local technological and scientific expertise abroad, they still perform their R\&D activities in their home countries to a larger extent due to superior appropriability conditions and home-country embeddedness. Irrespective of the model reported in Tables 2 and 3, domestic coopetition turned out as a significant predictor of new-tofirm or incremental innovations. These results are similar to arguments of Sok and O'Cass (2011) and Zhang et al. (2010), who suggested that as the differences are larger among international partners than among domestic firms, international coopetition facilitates more radical innovation as there is less knowledge redundancy. Our results also provide indirect support to the arguments that firms to a larger extent are involved in international relationships to access technological knowledge abroad to innovate for the world market, even if local embeddedness still remains highly important (Belderbos et al. 2013).

We argue that the intrinsic complexity of coopetitive relationships, due to the paradoxical nature of coopetition (Bengtsson et al. 2016), is further exacerbated by the complexities of international business and would, therefore, require more changes in an organization to manage such relationships. We, therefore, further hypothesized in $\mathrm{H} 2 \mathrm{a}$ and $\mathrm{H} 2 \mathrm{~b}$ that firms' ability to translate broader scope of international partnerships into innovation introduction is conditioned upon the magnitude of 


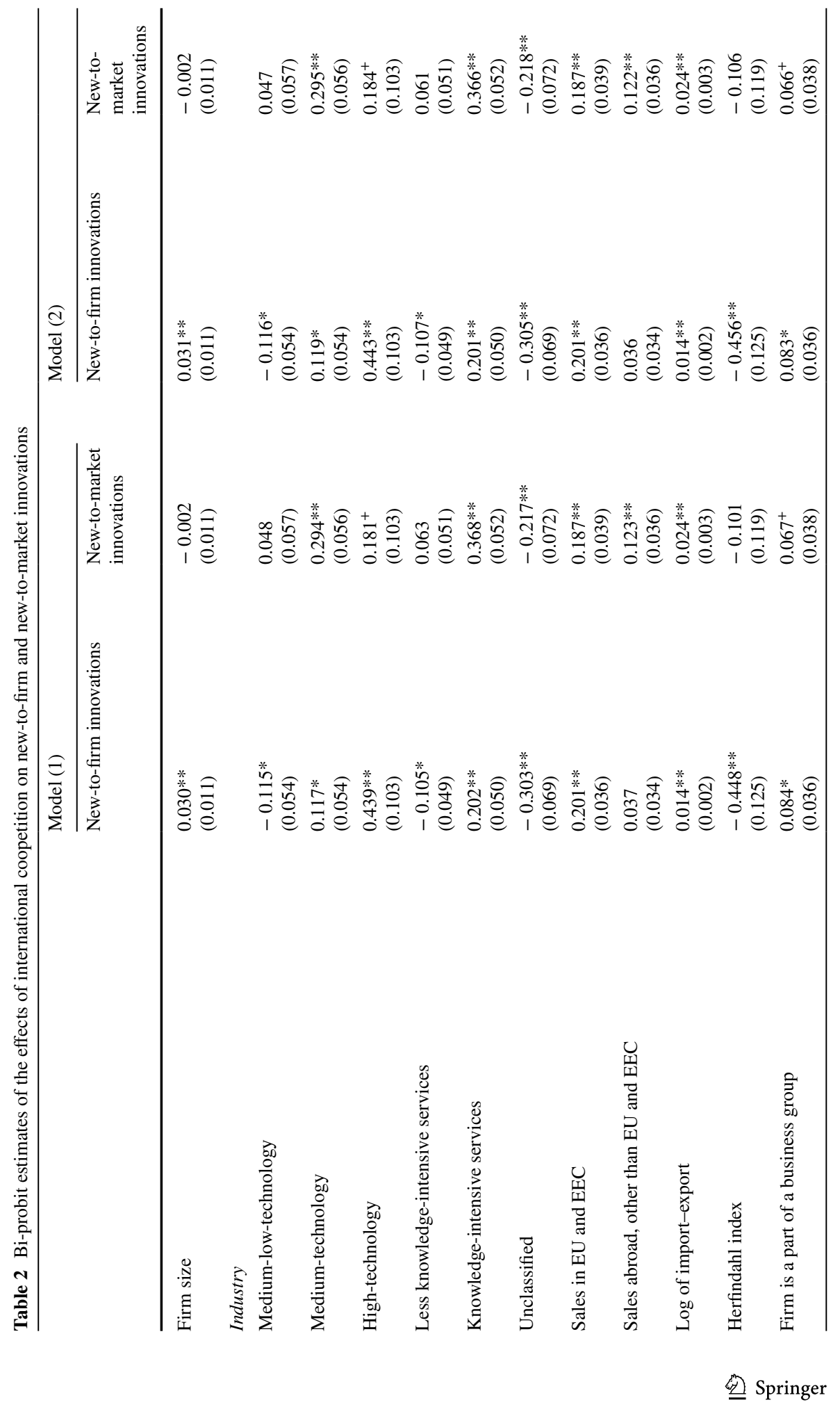




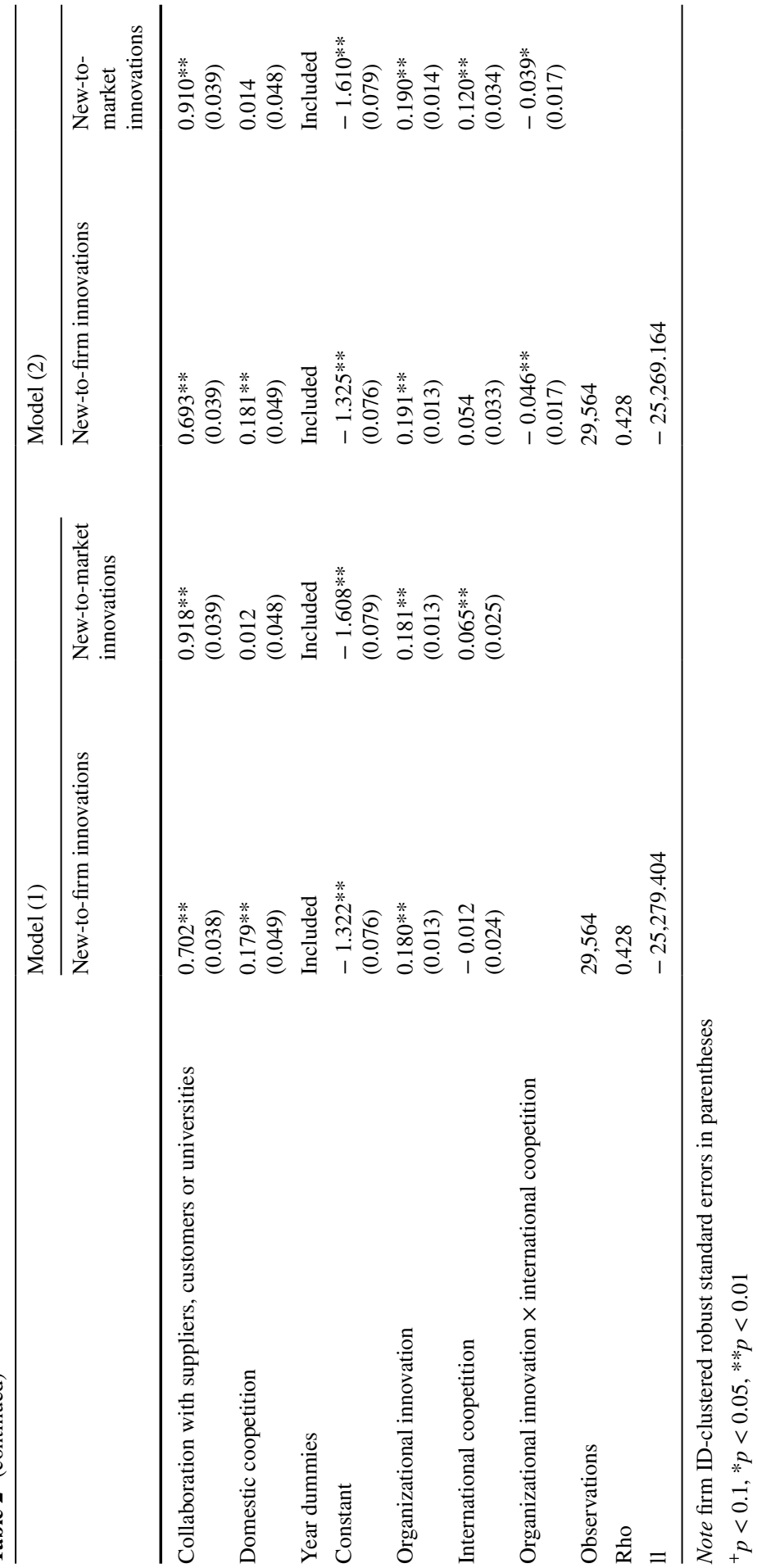




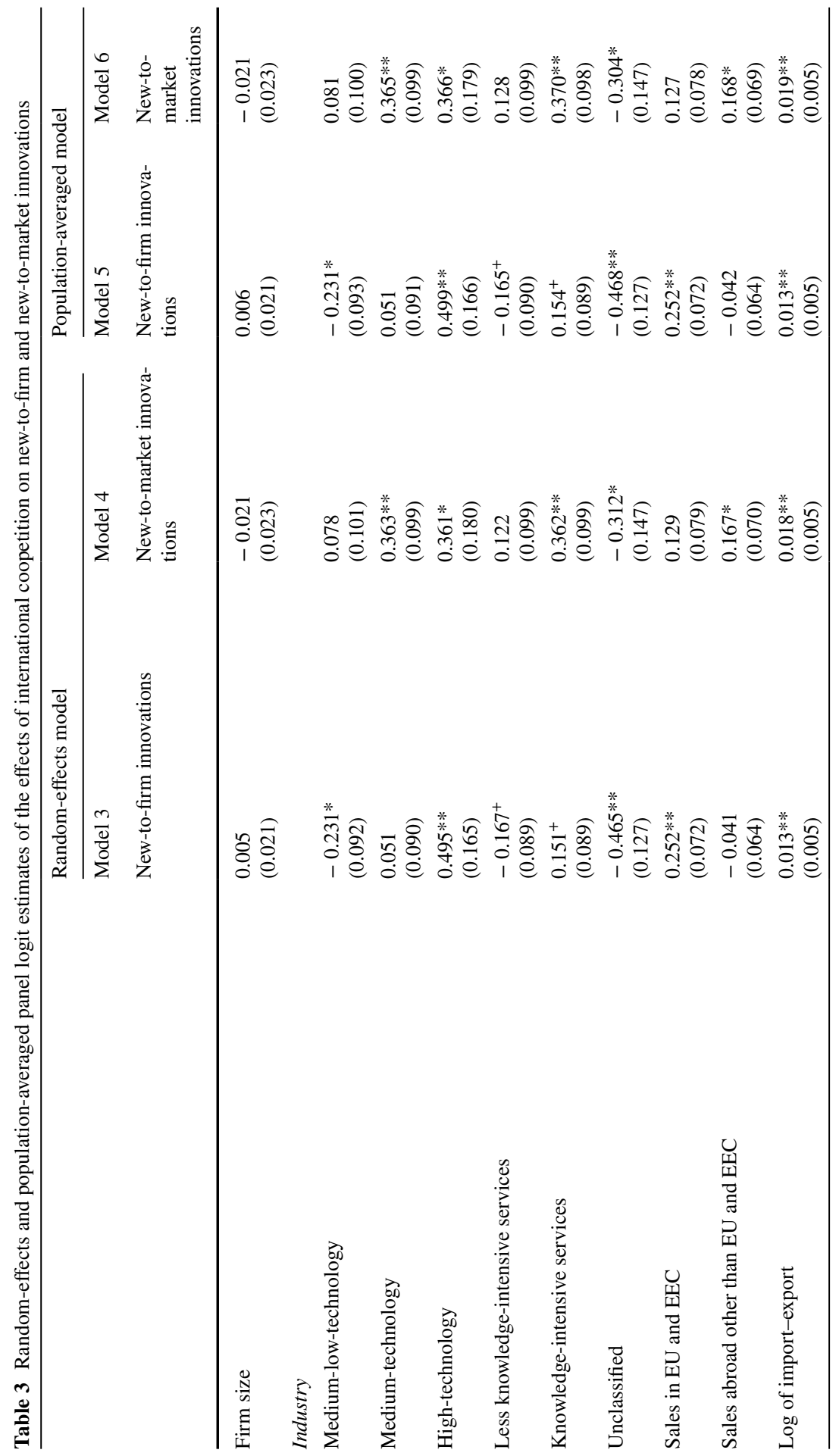




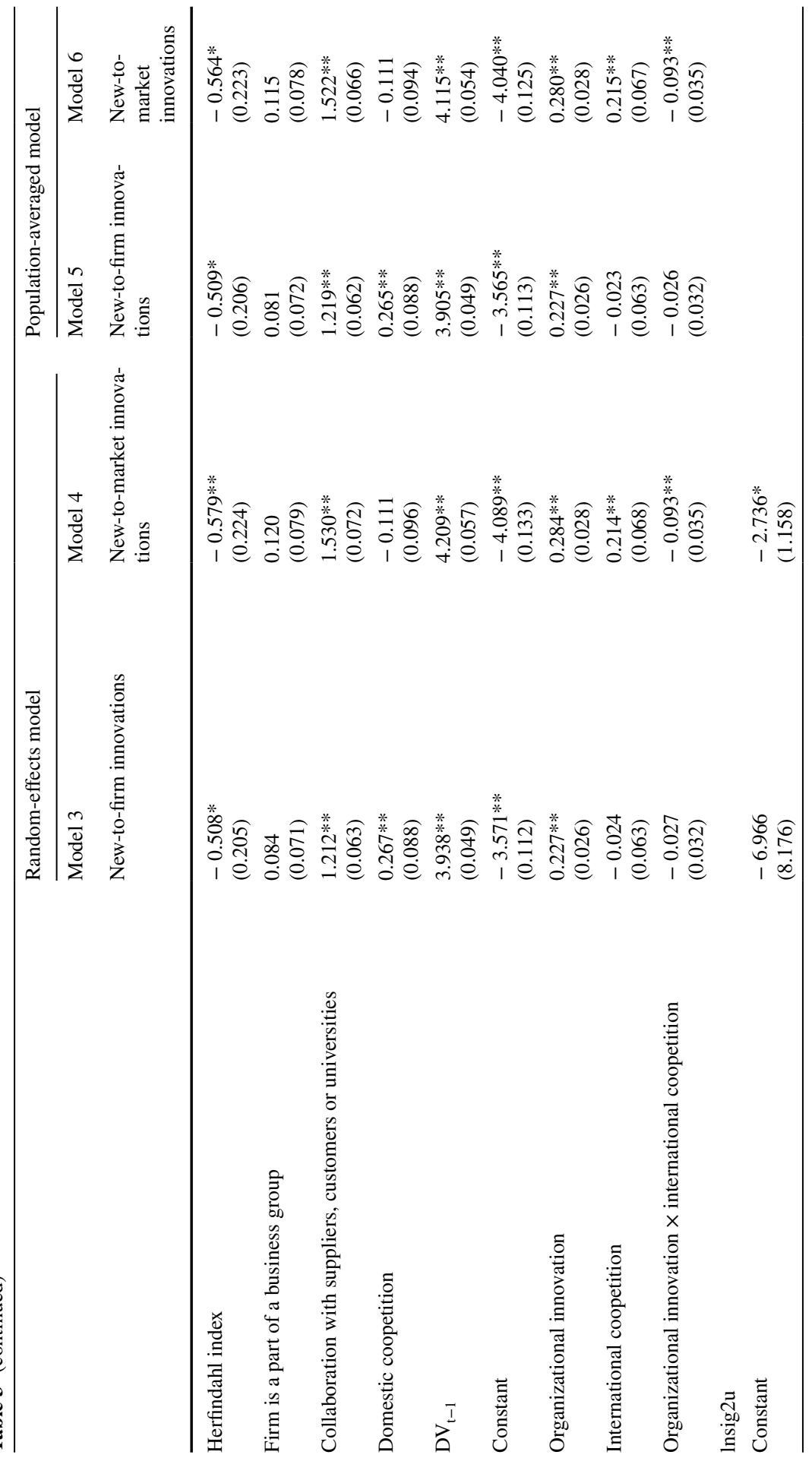




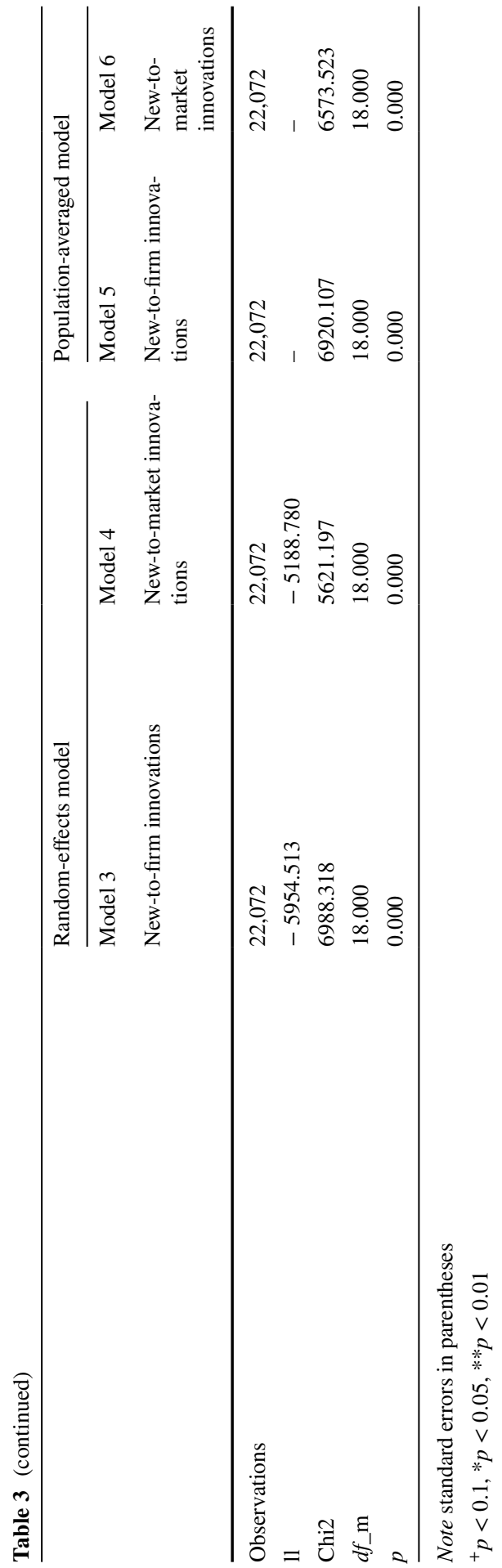


organizational innovations a firm needs to implement in conjunction with its innovation development and partnering endeavors. To aid interpretation of the findings, Fig. 2 plots predictive margins of organizational innovation at varying levels of the scope of international coopetition, as specified in Model 2. When accompanied by the high level of organizational innovation (OrgInn = 3) in the plot $(a)$, an increase in the scope of international coopetition reduces the likelihood of new-to-firm innovations, as suggested in H2a. Slopes of both lines in Fig. 2b suggest that an increase in the scope of international coopetition always has a positive effect on new-to-market innovations, yet the magnitude of such effect is almost negligible when accompanied by a high level of organizational innovation, as H2b suggests. Examination of the average marginal effect of organizational innovation given varying levels of international involvement in coopetition indicates that a high level of reorganizing consistently decreases a firm's ability to benefit from exposure to multiple international coopetitive partners when it comes to both new-to-firm and new-to-market innovations.

These findings have two important implications. First, research on the management of coopetition to a large extent focuses on managerial capabilities required to uphold the balance in coopetitive relationships or to mitigate the negative effects of resulting tensions, but how these capabilities are manifested in organizational mechanisms remains largely unknown (Park et al. 2014). Our results, constrained by the degree of measurement sophistication, provide an early indication that firms involved in coopetition undergo changes in organizing their activities. Furthermore,
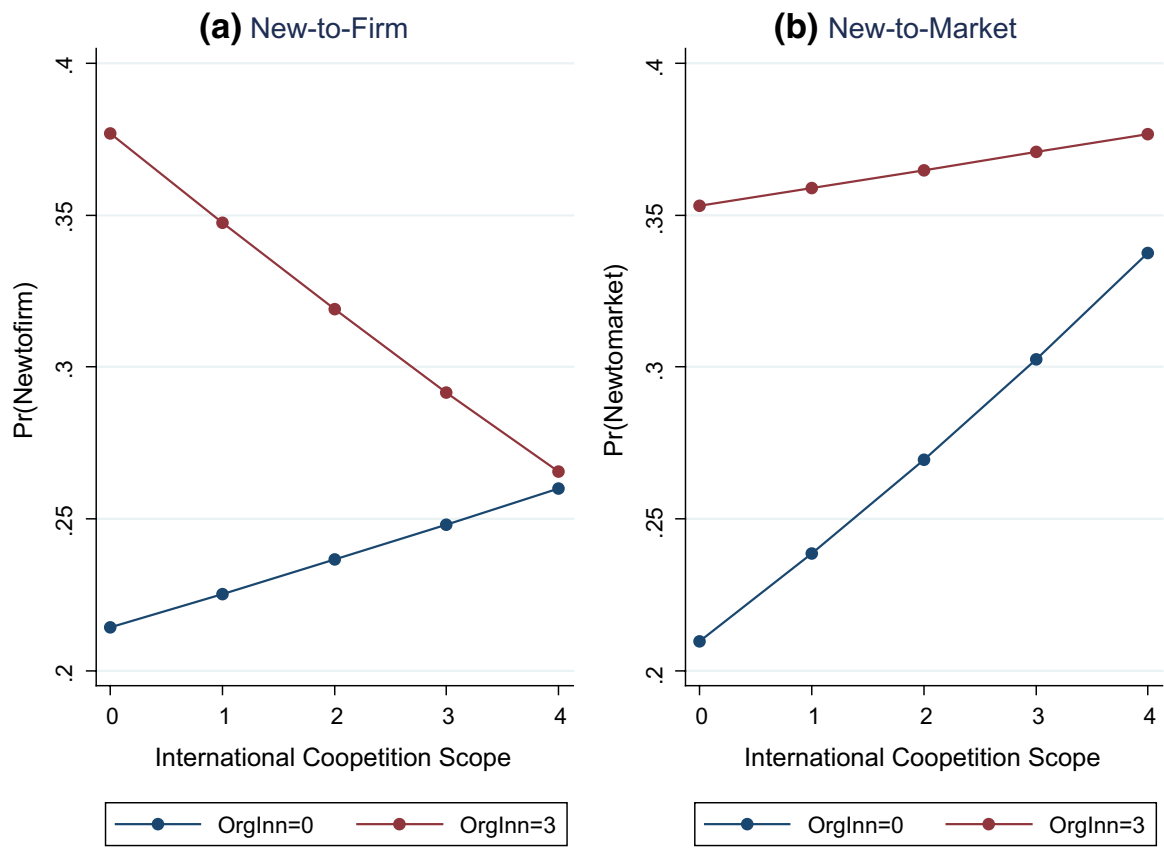

Fig. 2 Predictive margins of OrgInn at varying levels of the international coopetition scope 
in line with the expectation that the international nature of the relationship, due to its increased complexity and uncertainty, the findings indicate that international coopetition requires a firm to adjust even further and restricts its ability to benefit from the international exposure. Second, our results imply that having a broad range of coopetitive partners does not necessarily lead to superior innovative performance if the range is too broad and necessitates reorganization of a firm's processes. Although breath in external collaborations can be beneficial for innovation and can have positive learning effects over time, it has been suggested that there are limits to how much (Love et al. 2014). Even though a broad range of international coopetitive relationships might be motivated by goals other than innovation, for example, market expansion, our study strongly suggests that firms need to be well prepared when entering into such relationships.

Another point worth raising is that our study spans a period of time that includes the peak of the global financial crisis of 2007-2010 that saw firms collapse on an unprecedented scale (Riaz 2009), the 2012 crisis in the Eurozone (Barron et al. 2015,2016 ) and subsequent recovery. Technology-wise, the same time period saw the initial iPhone launch in 2007 and iPhone 5S in 2014. While our study does not seek to, and cannot, establish any relationship between the global technological or economic context and its effect on coopetition practices, the standardized nature of the surveys on which we relied suggests that the divergence of results on the coopetition-innovation link reported in studies conducted during different time periods (for example, Quintana-Garcia and Benavides-Velasco (2004) reporting a positive effect of coopetition on innovation and Mention (2011) finding it to be negative) might be attributed to the shifts in economic and technological regimes, which translate into changes in market uncertainty and competition intensity, both of which might affect the coopetition-innovation link (e.g., Ritala 2012).

Combined, our findings build on and extend existing research into coopetition and innovation, thereby answering calls for more quantitative empirical studies and further knowledge regarding the antecedents and implications for different types of innovation (Bouncken et al. 2015; Ritala et al. 2016). We demonstrate that firms involved in domestic coopetition consistently exhibit a higher rate of new-to-firm innovations and that international coopetition is associated with the more radical new-to-market ones. The literature highlights the importance of building capabilities to manage coopetitive tension (cf. Fernandez et al. 2014), and we contribute by elucidating the effect of actual changes in organizational routines and practices. In addition, prior studies have focused on coopetition within specific industries and contexts (Gast et al. 2015), but few researchers have specifically examined international coopetition. While international coopetition can be seen as an innate part of international business (Luo 2007) we illustrate that although domestic coopetition is still associated with most gains in incremental innovation, international coopetition intensifies the challenges inherent in coopetitive relationships and enables a higher rate of more radical new-to-market innovations.

While our study contributes to the theoretical understanding of international coopetition and innovation, it also provides immediate implications for managers, especially for those working in small and medium-sized enterprises that represent the bulk of our sample. We illustrate that partnering with competitors is consistently 
associated with superior innovative output both in terms of incremental and radical innovations. At the same time, managers should be aware of the challenging nature of such partnership that might require changes in the ways an organization operates. Expanding the international scope of coopetition also does not necessarily bring additional benefits in terms of innovative outputs as the challenges of cross-border interactions further accentuate the need to be prepared to adjust organizational routines and practices. This latter point also implies that even though coopeting internationally might grant access to unique knowledge and resources, domestic coopetition is still associated with consistent incremental innovation benefits. Hence, managers should carefully weigh the potential benefits offered by partnering with international competitors against the challenges of maintaining such partnerships.

Naturally, the results reported here should be considered within the limitations of the study, and overcoming those limitations opens up avenues for future work. Our dependent and independent variables build upon standardized surveys administered by the European governments, and such the empirical base contains both limitations and opportunities. On one hand, the degree of measurement sophistication of the key parameters in our study - coopetition and innovation - was limited by data availability (OECD 2005). To contribute to the discussion of how coopetition affects radical and incremental innovations, we used measures of new-to-market and new-to-firm innovations. Although introducing an innovation to a market is definitely an essential component of the innovation process, and geographical scope of partner location is an adequate proxy for international scope of coopetition, future work should include more detailed measures of both innovation and coopetition. On the other hand, the CISs are harmonized across the EU, and the natural next step would be to expand the one-country context of our study to multiple-country comparisons. In addition, the observed importance of organizational innovation for the relationship between coopetition and innovation suggests that future studies should look deeper into the demands imposed on and capabilities required from firms by the unique and paradoxical nature of a coopetitive relationship in international contexts.

In conclusion, while coopetition generally has been argued to lead to improved innovative outcomes, it is also recognized that the paradoxical nature of such relationships might require that a firm puts extra efforts and resources into managing and balancing contradictory logics contained within the simultaneity of cooperation and competition. In international coopetition, partners from different countries provide complementary resources beneficial for innovation but also increase risks involved. These two observations formed the departure point for the current study, which investigates whether expanding the scope of coopetitive partnerships internationally translates into further innovation gains due to the richer international resource base and whether the complexity of international environment places enhanced organizational demands on the participating firms. Using micro-matched register and survey data collected in Sweden over a seven-year period, we have found that firms cooperating with competitors internationally are more likely to exhibit higher propensity to introduce more radical (new-to-market) innovations, yet this effect is conditioned upon the magnitude of organizational changes a firm undergoes. 
Open Access This article is distributed under the terms of the Creative Commons Attribution 4.0 International License (http://creativecommons.org/licenses/by/4.0/), which permits unrestricted use, distribution, and reproduction in any medium, provided you give appropriate credit to the original author(s) and the source, provide a link to the Creative Commons license, and indicate if changes were made.

\section{References}

Autio E, Sapienza HJ, Almeida JG (2000) Effects of age at entry, knowledge intensity, and imitability on international growth. Acad Manag J 43(5):909-924

Barron A, Hultén P, Vanyushyn V (2015) Country-of-origin effects on managers' environmental scanning behaviours-evidence from the political crisis in the Eurozone. Environ Plan C 33(3):601-619

Barron A, Hultén P, Vanyushyn V (2016) The role of political intelligence in firms' export diversification decisions. J Small Bus Manag 54(4):1126-1146

Baumard P (2009) An asymmetric perspective on coopetitive strategies. Int J Enterp Small Bus 8(1):6-22

Beamish PW, Kachra A (2004) Number of partners and JV performance. J World Bus 39(2):107-120

Belderbos R, Leten B, Suzuki S (2013) How global is R\&D? Firm-level determinants of home-country bias in R\&D. J Int Bus Stud 44(8):765-786

Bengtsson M, Kock S (2000) Coopetition' in business networks, to cooperate and compete simultaneously. Ind Mark Manag 29(5):411-426

Bengtsson M, Raza-Ullah T, Vanyushyn V (2016) The coopetition paradox and tension: the moderating role of coopetition capability. Ind Mark Manag 53(1):19-30

Bouncken RB, Fredrich V (2012) Coopetition: performance implications and management antecedents. Int J Innov Manag 16(05):1250028

Bouncken RB, Kraus S (2013) Innovation in knowledge-intensive industries: the double-edged sword of coopetition. J Bus Res 66(10):2060-2070

Bouncken RB, Gast J, Kraus S, Bogers M (2015) Coopetition: a systematic review, synthesis, and future research directions. Rev Manag Sci 9(3):577-601

Bouncken RB, Plüschke BD, Pesch R, Kraus S (2016) Entrepreneurial orientation in vertical alliances: joint product innovation and learning from allies. Rev Manag Sci 10(2):381-409

Bouncken RB, Fredrich V, Ritala P, Kraus S (2017) Coopetition in new product development alliances: advantages and tensions for incremental and radical innovation. Br J Manag (in press)

Brandenburger A, Nalebuff B (1996) Co-opetition. Doubleday, New York

Cader HA, Leatherman JC (2011) Small business survival and sample selection bias. Small Bus Econ 37(2):155-165

Cassiman B, Di Guardo MC, Valentini G (2009) Organising R\&D projects to profit from innovation: insights from co-opetition. Long Range Plan 42(2):216-233

Chen MJ (2008) Reconceptualizing the competition-cooperation relationship: a transparadox perspective. J Manag Inq 17(4):288-304

Chetty SK, Stangl LM (2010) Internationalization and innovation in a network relationship context. Eur J Mark 44(11/12):1725-1743

Cohen WM, Levinthal DA (1990) Absorptive capacity: a new perspective on learning and innovation. Adm Sci Q 35(1):128-152

Das TK, Teng BS (2000) Instabilities of strategic alliances: an internal tensions perspective. Organ Sci 11(1):77-101

Davidson WH, McFetridge DG (1985) Key characteristics in the choice of international technology transfer mode. J Int Bus Stud 16(2):5-21

Dewar RD, Dutton JE (1986) The adoption of radical and incremental innovations: an empirical analysis. Manag Sci 32(11):1422-1433

Estrada I, Faems D, de Faria P (2016) Coopetition and product innovation performance: the role of internal knowledge sharing mechanisms and formal knowledge protection mechanisms. Ind Mark Manag 53(1):56-65

Fang SR, Chang YS, Peng YC (2011) Dark side of relationships: a tensions-based view. Ind Mark Manag 40(5):774-784 
Fernandez AS, Le Roy F, Gnyawali DR (2014) Sources and management of tension in co-opetition case evidence from telecommunications satellites manufacturing in Europe. Ind Mark Manag 43(2):222-235

Gast J, Filser M, Gundolf K, Kraus S (2015) Coopetition research: towards a better understanding of past trends and future directions. Int J Enterp Small Bus 24(4):492-521

Ghemawat P (2001) Distance still matters: the hard reality of global expansion. Harv Bus Rev 79(8):137-147

Glaister KW, Buckley PJ (1999) Performance relationships in UK international alliances. Manag Int Rev 39(2):123-147

Gnyawali DR, Park B-J (2011) Co-opetition between giants: collaboration with competitors for technological innovation. Res Policy 40(5):650-663

Greene WH (2008) Econometric analysis, 6th edn. Prentice-Hall, Upper Saddle River

Hultén P, Vanyushyn V (2010) A new research paradigm to analyze the threats against fair competition in the global marketplace. Compet Rev Int Bus J 20(2):182-193

Kim J, Parkhe A (2009) Competing and cooperating similarity in global strategic alliances: an exploratory examination. Br J Manag 20(3):363-376

Kogut B, Singh H (1988) The effect of national culture on the choice of entry mode. J Int Bus Stud 19(3):411-432

Kranenburg H, Hagedoorn J, Lorenz-Orlean S (2014) Distance costs and the degree of inter-partner involvement in international relational-based technology alliances. Glob Strategy J 4(4):280-291

Kraus S, Pohjola M, Koponen A (2012) Innovation in family firms: an empirical analysis linking organizational and managerial innovation to corporate success. Rev Manag Sci 6(3):265-286

Kraus S, Meier F, Niemand T, Bouncken RB, Ritala P (2017) In search for the ideal coopetition partneran experimental study. Rev Manag Sci (in press)

Le Roy F, Robert M, Lasch F (2016) Choosing the best partner for product innovation. Int Stud Manag Organ 46(2-3):136-158

Lew YK, Sinkovics RR (2013) Crossing borders and industry sectors: behavioral governance in strategic alliances and product innovation for competitive advantage. Long Range Plan 46(1):13-38

Li L, Qian G, Qian Z (2012) Early internationalization and performance of small high-tech 'bornglobals'. Int Mark Rev 29(5):536-561

Love JH, Roper S, Vahter P (2014) Learning from openness: the dynamics of breadth in external innovation linkages. Strateg Manag J 35(11):1703-1716

Luo Y (2004) Coopetition in international business. CBS Press, Køge

Luo YD (2007) A coopetition perspective of global competition. J World Bus 42(2):129-144

Makino S, Chan CM, Isobe T, Beamish PW (2007) Intended and unintended termination of international joint ventures. Strateg Manag J 28(11):1113-1132

McCutchen WW Jr, Swamidass PM, Teng BS (2008) Strategic alliance termination and performance: the role of task complexity, nationality, and experience. J High Tech Manag Res 18(2):191-202

Mention AL (2011) Co-operation and co-opetition as open innovation practices in the service sector: which influence on innovation novelty? Technovation 31(1):44-53

Miller KD (1992) A framework for integrated risk management in international business. J Int Bus Stud 23(2):311-331

Nielsen BB (2007) Determining international strategic alliance performance: a multidimensional approach. Int Bus Rev 16(3):337-361

Nielsen BB, Nielsen S (2009) Learning and innovation in international strategic alliances: an empirical test of the role of trust and tacitness. J Manag Stud 46(6):1031-1056

Nieto MJ, Santamaría L (2007) The importance of diverse collaborative networks for the novelty of product innovation. Technovation 27(6):367-377

OECD (2005) Oslo Manual—Guidelines for collecting and interpreting innovation data. OECD/Eurostat

OECD (2011) ISIC rev. 3 Technology intensity definition. http://www.oecd.org/sti/ind/48350231.pdf. Accessed 26 June 2017

Park BJR, Srivastava MK, Gnyawali DR (2014) Walking the tight rope of coopetition: impact of competition and cooperation intensities and balance on firm innovation performance. Ind Mark Manag 43(2):210-221

Quintana-Garcia C, Benavides-Velasco CA (2004) Cooperation, competition, and innovative capability: a panel data of European dedicated biotechnology firms. Technovation 24(12):927-938

Raza-Ullah T (2017a) A theory of experienced paradoxical tension in co-opetitive alliances. Doctoral dissertation, Umeå universitet, Studier i företagsekonomi. Serie B, ISSN 0346-8291; 97 
Raza-Ullah T (2017b) The role of emotional ambivalence in coopetition alliances. Acad Manag Proc 2017(1):17710

Raza-Ullah T, Bengtsson M, Kock S (2014) The coopetition paradox and tension in coopetition at multiple levels. Ind Mark Manag 43(2):189-198

Riaz S (2009) The global financial crisis: an institutional theory analysis. Crit Perspect Int Bus 5(1/2):26-35

Ritala P (2012) Coopetition strategy-When is it successful? Empirical evidence on innovation and market performance. Br J Manag 23(3):307-324

Ritala P, Hurmelinna-Laukkanen P (2009) What's in it for me? Creating and appropriating value in innovation-related coopetition. Technovation 29(12):819-828

Ritala P, Hurmelinna-Laukkanen P (2013) Incremental and radical innovation in coopetition-the role of absorptive capacity and appropriability. J Prod Innov Manag 30(1):154-169

Ritala P, Sainio LM (2014) Coopetition for radical innovation: technology, market and business-model perspectives. Tech Anal Strat Manag 26(2):155-169

Ritala P, Kraus S, Bouncken RB (2016) Introduction to coopetition and innovation: contemporary topics and future research opportunities. Int J Technol Manag 71(1/2):1-9

Sampson RC (2007) R\&D alliances and firm performance: the impact of technological diversity and alliance organization on innovation. Acad Manag J 50(2):364-386

Schmiele A, Sofka W (2007) Internationalizing R\&D Co-opetition: Dress for the Dance with the Devil. ZEW-Centre for European Economic Research Discussion Paper No. 07-045

Sok P, O'Cass A (2011) Achieving superior innovation-based performance outcomes in SMEs through innovation resource-capability complementarity. Ind Mark Manag 40(8):1285-1293

Taylor M, Jack R (2013) Understanding the pace, scale and pattern of firm internationalization: an extension of the 'born global' concept. Int Small Bus J 31(6):701-721

Wu J (2012) Technological collaboration in product innovation: the role of market competition and sectoral technological intensity. Res Policy 41(2):489-496

Wu J (2014) Cooperation with competitors and product innovation: moderating effects of technological capability and alliances with universities. Ind Mark Manag 43(2):99-209

Yami S, Nemeh A (2014) Organizing coopetition for innovation: the case of wireless telecommunication sector in Europe. Ind Mark Manag 43(2):250-260

Yan A, Zeng M (1999) International joint venture instability: a critique of previous research, a reconceptualization, and directions for future research. J Int Bus Stud 30(2):397-414

Zahra SA, Usbasaran D, Newey LR (2009) Social knowledge and SMEs' innovative gains from internationalization. Eur Manag Rev 6(2):81-93

Zhang HS, Shu CL, Jiang X, Malter AJ (2010) Managing knowledge for innovation: the role of cooperation, competition, and alliance nationality. J Int Mark 18(4):74-94 